\title{
The history of the "fast sound" in liquid water
}

\author{
G.Ruocco ${ }^{1}$, F.Sette ${ }^{2}$ \\ ${ }^{1}$ Dipartimento di Fisica, Universita' di Roma "La Sapienza", Piazza Aldo Moro 2, I-00185 Roma, Italy \\ 2 European Synchrotron Radiation Facility, B.P. 220 F-38043 Grenoble, Cedex France
}

Received February 12, 2008

\begin{abstract}
This paper aims to discuss the present understanding of the high frequency dynamics in liquid water, with particular attention to a specific phenomenon - the so-called fast sound-since its first appearance in the literature up to its most recent explanation. A particular role in this history is played by the inelastic x-ray scattering (IXS) technique, which - with its introduction in the middle '90- allowed to face a large class of problems related to the high frequency dynamics in disordered materials, such as glass and liquids. The results concerning the fast sound in water obtained using the IXS technique are here compared with the inelastic neutron scattering (INS) and molecular dynamics simulation works. The IXS work has allowed us to demonstrate experimentally the existence of two branches of collective modes in liquid water: one linearly dispersing with the momentum (apparent sound velocity of $\approx 3200 \mathrm{~m} / \mathrm{s}$, the "fast sound") and the other at almost constant energy $(5 \div 7 \mathrm{meV})$. It has been possible to show that the dispersing branch originates from the viscoelastic bend up of the ordinary sound branch. The study of this sound velocity dispersion, marking a transition from the ordinary sound, $c_{\mathrm{O}}$ to the "fast sound", $c_{\infty}$, as a function of temperature, has made it possible to relate the origin of this phenomenon to a structural relaxation process, which presents many analogies to those observed in glass-forming systems. The possibility to estimate from the IXS data the value of the relaxation time, $\tau$, as a function of temperature leads to relating the relaxation process to the structural re-arrangements induced by the making and breaking of hydrogen bonds. In this framework, it is then possible to recognize an hydrodynamical "normal" regime, i. e. when one considers density fluctuations whose period of oscillation is on a timescale long with respect to $\tau$, and a solid-like regime in the opposite limit. In the latter regime, the density fluctuations feel the liquid as frozen and the sound velocity is much higher: this is "fast sound" whose value is equivalent to the sound velocity found in crystalline ice.
\end{abstract}

Key words: water, inelastic $x$-ray scattering, sound propagation, liquids, glasses

PACS: $61.10 . E q, 63.50 .+x, 78.70 . C k$

\section{Introduction}

In 1974 Rahman and Stillinger [1], while analyzing the dynamic structure factor $(S(q, \omega))$ of liquid water calculated by molecular dynamics simulations, discovered the existence of two excitations in the $3-6 \mathrm{~nm}^{-1}$ exchanged momentum $(q)$ region. The explored $q$ range was not large enough to establish the propagating nature of these modes, but their energies were such that, if associated to propagating modes $\omega=c q$, they would give velocities of sound, $c \approx 1500$ $\mathrm{m} / \mathrm{s}$ and $\approx 3000 \mathrm{~m} / \mathrm{s}$ respectively. The first value is consistent with the ordinary sound velocity in water. The other mode was, at that time, interpreted as a band of excitations associated with the hydrogen bond network, and propagating with a much higher sound velocity: the "fast sound".

The simulation experiment of Rahman and Stillinger, whose results concerning the $q$-dependence of the peak positions are reported in figure 1 as open symbols, induced a lot of interest, motivating further simulation work, as well as attempts to experimentally determine the $S(q, \omega)$ in the $q-\omega$ region of interest. Two experimental determinations of the coherent dynamic structure factor of liquid $\mathrm{D}_{2} \mathrm{O}$ were in fact performed using neutron spectroscopy respectively in 1978 and in 1985 . The first experiment was executed by P. Bosi and collaborators [2] using a triple axis spectrometer on the TRIGA reactor (Enea-Casaccia, Rome, I). The kinematics region explored in this experiment, however, did not permit to cover the $q-\omega$ region where the excitations branch associated with the fast sound was expected. The low energy band was nevertheless observed, but, as seen in figure 1 (full diamonds), it showed a very weak $q$ dependence. The excitation energy observed at the lowest 
$q$ value of $5 \mathrm{~nm}^{-1}$ is consistent with a speed of sound of $1500 \mathrm{~m} / \mathrm{s}$, and therefore with the low energy mode of the Rahman and Stillinger MD simulation. In a second experiment, performed in 1985 by J. Teixeira and collaborators [3] on the IN8 spectrometer at the ILL (Grenoble, F), the use of higher energy incident neutrons permitted to extend the kinematics region up to the expected dispersion law of the fast sound. This experiment made it possible to demonstrate the existence of a collective excitation propagating with $c \approx 3300 \mathrm{~m} / \mathrm{s}$ in the $q=3.5-6 \mathrm{~nm}^{-1}$ region. The low energy band seen by P. Bosi et al. [2], however, was not observed in this second experiment due to the limited energy resolution $(\Delta E=4.5 \mathrm{meV})$ and the large quasi-elastic contribution to the scattering signal.

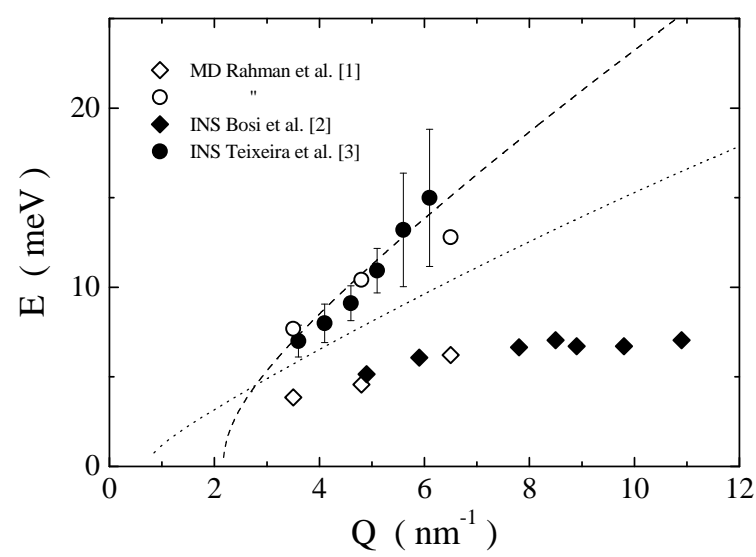

Figure 1. Peak position of the two excitations discovered in the $S(q, \omega)$ of liquid water. The energies of the peaks are reported instead of their frequencies $(E=\hbar \omega)$. The open symbols represent the excitation energy for the normal (open diamond) and fast (open square) sound found by Rahman and Stillinger [1] by MD simulation. The full symbols (full diamond [2]; full circle [3]) are the corresponding experimental findings. The dashed and dotted lines are the kinematics limits of the inelastic neutron scattering experiments for the incident neutron energy and the minimum scattering angle utilized in the two experiments. Only the $E-q$ region that lies below the lines can be accessed experimentally. The dashed line indicates the upper limit of the kinematics region of the Bosi et al. experiment [2]; it is clear that the high frequency mode was not accessible. The dotted line indicates the upper limit of the kinematics region accessible to the Texeira et al. experiment [3]. It is evident that in this case the additionally accessible region is very valuable to get information on the pattern of the excitations in liquid water. However the increased energy resolution $(4.5 \mathrm{meV})$, as a consequence of the higher energy of the incoming neutrons, did not permit to detect the low energy mode in this experiment.

These findings motivated a large number of molecular dynamics simulations of liquid water [413], with the purpose of investigating the ultimate origin of the fast sound phenomenon, and, in particular, to verify the existence of two different propagating collective modes. The body of MD simulations leads to the following results: $(i)$ The low energy branch found by Rahman e Stillinger, in agreement with the experimental data of Bosi et al., has an energy $E=4-6 \mathrm{meV}$ and in the $q$ range explorable by MD- its dispersion with $q$ is very weak. The modes belonging to this branch are better visible when using potential models (like ST2 and SPC) that emphasize the tetrahedral structure of the liquid. This band has been tentatively assigned to a $\mathrm{O}-\mathrm{O}-\mathrm{O}$ bending vibration [8]. ( $i i$ ) It is not possible to exclude that the high energy branch, arising from a collective dynamics propagating with a speed of sound of $\approx 3300 \mathrm{~m} / \mathrm{s}$, is the high frequency evolution of the normal sound branch observed in the $q=0$ limit, where it propagates with $\approx 1500 \mathrm{~m} / \mathrm{s}$. Such a dependence on $q$ of the sound velocity may have its origin in the details of the intermolecular interaction, and its large value may be due to the strong electrostatic $\mathrm{O}-\mathrm{H}$ intermolecular interaction, leading to an average $\mathrm{O}-\mathrm{O}$ distance well below the Lennard-Jones $\sigma$ value for oxygen atoms [10]. (iii) The analysis of the partial $S_{\mathrm{OO}}(q, \omega)$ and $S_{\mathrm{HH}}(q, \omega)$ indicates that the hydrogen dynamics is confined to much higher energies (above $50 \mathrm{meV}$ ), and therefore it is not likely to be associated with the fast sound branch [7]. 
The possibility that the observed branch dispersing with $3000 \mathrm{~m} / \mathrm{s}$ is nothing else but the continuation at high $q$-values of the normal sound is suggested by the comparison with other liquids, in particular those in their supercooled phase. In the supercooled regime one observes a change in the value of the sound velocity at $q$-values such that the inverse of the frequency of the mode equals the system relaxation time. Indeed, an analysis in this direction of the Brillouin light scattering spectra in water $[14,15]$ confirms this possibility, predicting the doubling of the speed of sound at high frequency.

Following the two pioneering INS experiments by Bosi et al. [2]. and by Teixeira et al. [3], another neutron experiment was performed in 1994 on the spectrometer MARI at the RAL (Chilton, Didcot, UK) [16]. Limitations on the available kinematics region, however, again did not permit to obtain new information on the fast sound branch. It confirmed, nevertheless, the results obtained sixteen years before by Bosi et al. [2] on the existence of a $5-7 \mathrm{meV}$ almost non-dispersing branch.

In figure 2, we summarize in the exchanged energy-momentum plane the position of the excitations in liquid water as derived from selected MD studies and from the neutron experiments. We also report, as a dashed line the linear dispersion that one would have if the speed of sound in the high frequency region were the same as in the $q=0$, limit, i. e. the ordinary sound $c_{\mathrm{o}}=1500 \mathrm{~m} / \mathrm{s}$.

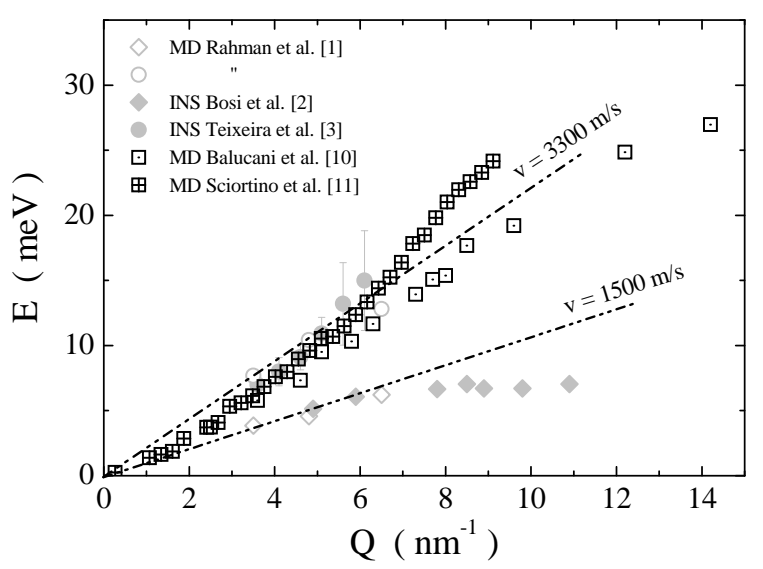

Figure 2. Excitation energies for the fast sound mode derived in selected MD works (dotted squares [10]; crossed squares [11]) reported as a function of $q$ together with the corresponding quantities of figure 1 (light grey symbols). The two lines are the dispersion relations expected for the prosecution at high $q$ of the hydrodynamics sound modes $(\approx 1500 \mathrm{~m} / \mathrm{s})$ and the fast sound dispersion derived from the experiment of Teixeira et al. [3] $(\approx 3300 \mathrm{~m} / \mathrm{s})$.

In a nutshell, the situation in 1994 was not satisfactory at all. On the one hand, the main reason was a large scatter of results in the simulation work (due to the different interaction potential models), and, on the other hand, the kinematics limitations of the neutron spectroscopy studies, which did not permit to cover simultaneously the $q-E$ region of the two branches. This would have provided the definitive evidence for the existence of the two modes, and it would have permitted to start an experimental investigation in order to understand their origin, and, more generally, their relation to the properties of the liquid state.

This historical moment saw the birth of the inelastic x-rays spectroscopy as a probe complementary to neutrons, a probe that has given important new information - among others - on the issue of the fast sound in liquid water.

\section{The early IXS measurements}

Historically, during the development and commissioning phase of the first IXS spectrometer at the BL21 (now ID16) beamline at the European Synchrotron Radiation Facility (ESRF)in Grenoble, France, there have been three experiments at successive times which were performed following relevant improvements in the energy resolution of the new instrument. They were respectively 
carried out in March 1995 with 5 meV energy resolution [17], in June 1995 with $3.5 \mathrm{meV}$ [18], and in February 1996 with $1.5 \mathrm{meV}$ [19]. The first IXS spectra measured on liquid water, with $3 \mathrm{meV}$ energy resolution, at $T=5 \mathrm{C}$ and saturated vapor pressure are reported in figure 3 as a function of the energy transfer, $E$, and for different values of momentum transfer, $q$. The spectra are shown together with the resolution function. This function has been arbitrarily aligned with the central peak $(E=0)$, and scaled to its intensity, in order to emphasize the presence of an inelastic signal whose shape and intensity changes with $q$. Specifically, we observe that the energy distribution of this $q$-dependent inelastic signal moves towards higher values with increasing $q$.

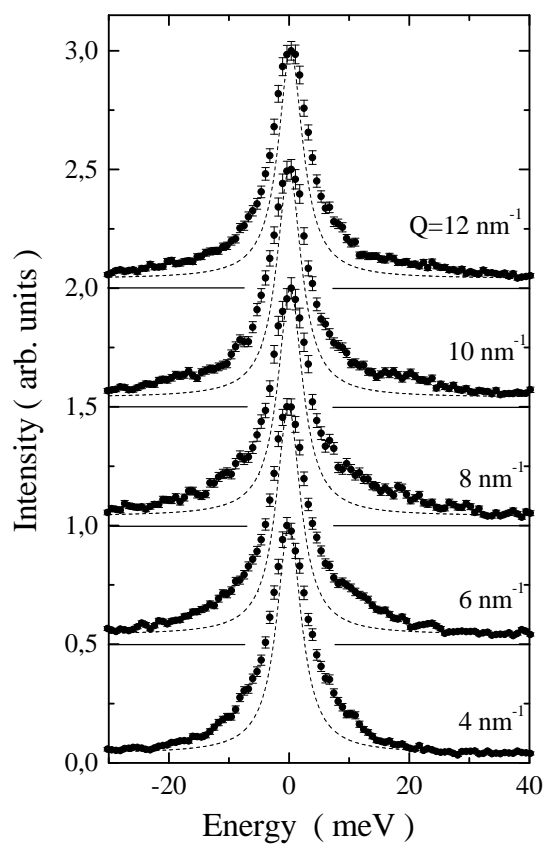

Figure 3. Inelastic x-ray scattering spectra of $\mathrm{H}_{2} \mathrm{O}$ taken with $3 \mathrm{meV}$ energy resolution at $5 \mathrm{C}$ and at the indicated $q$ values. The experimental data (full circles) are shown with the error bars. The dashed lines under the central peaks are the resolution function (upward shifted to account for the instrumental background), shown to emphasize the $q$-dependent intensity on the sides of the central peak. The data are normalized to the intensity of the central peak maximum. The integration time for each data point was $120 \mathrm{~s}$.

According to the basic theory of the IXS scattering, in a system like liquid water the experimental data - as those reported in figure 3 - directly reflect the shape of the $S(q, \omega)$. In order to describe their $q$ and $E$ dependencies, one must adopt some model function. From the fitting of the data one simply obtains different parameters, among which the average excitation energy, $\Omega(q)$, the energy width, $\Gamma(q)$, and the intensity ratio of the inelastic to elastic signal, $I(q) / I_{\mathrm{c}}(q)$. The simplest model function, that was used to fit the first IXS spectra and that preserves the basic features of the Brillouin triplet observed in the hydrodynamic limit was made out of a central peak and two - Stokes and Anti-Stokes - inelastic features. The central peak, as in the Brillouin triplet, is modelled by a Lorentzian function, while the side peaks are represented by a Damped Harmonic Oscillator (DHO) function [20]. The choice of the DHO is motivated by various arguments: the first one is related to the fact that one can derive this lineshape using the Markovian approximation for the memory function (see later), i. e. one assumes that the timescale of the considered density fluctuations, and the reaction of the surrounding medium, is much faster than the relaxation time associated with any relaxation process active in the system. This corresponds to a model of the memory function entering the generalized Langevin equation made out of a constant and a $\delta(t)$ function [21]. A second point is simply related to the fact that this model is routinely utilized in the analysis of neutron data and MD simulation spectra of disordered systems, and therefore its use enables a direct comparison with the existing work in liquid water. 
The values of the excitations energies, $\Omega(q)$, derived from the fit to the data in figure 3 are reported in figure 4 together with the corresponding quantities derived by Teixeira et al. from their neutron data. We observe in the IXS data a linear dispersion with $c=3200 \pm 100 \mathrm{~m} / \mathrm{s}$, and a very good overlap between the x-ray and neutron data, in spite of the fact that the neutron data were taken on $\mathrm{D}_{2} \mathrm{O}$ and the x-ray ones on $\mathrm{H}_{2} \mathrm{O}$.

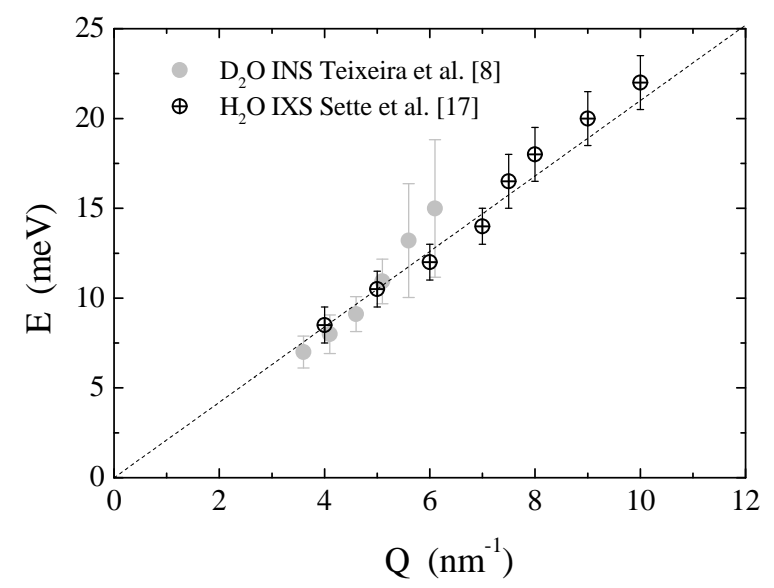

Figure 4. The excitation energy, $\Omega(q)$, as obtained from the fit to the data of figure 3 (crossed circles) is reported as a function of $q$ and compared with the similar quantity measured by INS by Teixeira et al. [3] (grey full circles). The dashed line indicates the best linear fit up to $10 \mathrm{~nm}^{-1}$ of the IXS derived $\Omega(q)$, and its slope corresponds to a speed of sound of $3200 \pm 100 \mathrm{~m} / \mathrm{s}$.

The results of the fitting to the x-ray data, when compared with the neutron data of Teixeira et al., make it possible to clarify some issues: (i) In the $4-10 \mathrm{~nm}^{-1} q$ region there exists an excitation in liquid water that propagates with a velocity of sound more than double the ordinary sound velocity. (ii) The energy of these excitations at a given $q$ is, within the error bar, the same in heavy and light water, without an isotopic shifts that can be related directly to the mass difference between $\mathrm{H}$ and $\mathrm{D}$. The studies on both $\mathrm{D}_{2} \mathrm{O}$ and $\mathrm{H}_{2} \mathrm{O}$ show in fact that there is a reduction of the excitation energies in $\mathrm{D}_{2} \mathrm{O}$ with respect to $\mathrm{H}_{2} \mathrm{O}$ consistent with the factor $\sqrt{18 / 20} \approx 0.95$, expected from the total mass difference between the two molecules. It is then possible to conclude that this excitation involves the centre of mass of the whole molecule, and it is not limited predominantly to the motion of the lighter hydrogen atoms.

The IXS data reported in figure 3 are dominated by the elastic component and by the fast sound modes. The presence of a feature at $E \approx 5 \mathrm{meV}$, as that reported in $[2,16]$, is overwhelmed by the central peak, broadened by the experimental resolution. In order to asses its existence, the IXS spectra have been measured with increased statistical accuracy at the selected $q$ values. These spectra are reported in figure 5, and, beside the inelastic scattered intensity dispersing with $q$, it is now possible to observe a new weakly dispersing feature with $4-6 \mathrm{meV}$ energy transfer. This is better seen in the insets of figure 5. This feature is observed only in the spectra with $q$ larger than $4 \mathrm{~nm}^{-1}$, and is no longer detected in the spectra at small $q$.

Similarly to the data in figure 3 , the data at $q \geqslant 4 \mathrm{~nm}^{-1}$ were fitted by a Lorentzian for the central peak, and two DHO models to represent the modes. The energies of the excitations, determined from the fit and corresponding to the DHO fitting parameter $\Omega(q)$, are reported in figurex 6 together with the simulation and neutron results of figure 2 . The different measurements of the dispersing excitations are consistent among each other in the common $q$ range. Therefore, one concluded that the IXS measurements confirm the existence of two modes in the high frequency dynamics of liquid water at $q$ values larger than $4 \mathrm{~nm}^{-1}$.

A careful study of the $S(q, \omega)$ at $q$ values smaller than $4 \mathrm{~nm}^{-1}$, on the contrary, shows only one excitation, and this excitation disperses with $q$. These data are reported in the IXS data of figure 7, where it is no longer possible to observe an excitation in the $4-5 \mathrm{meV}$ energy region. Most important, the DHO analysis of these data shows us that, in this small- $q$ region, there is 


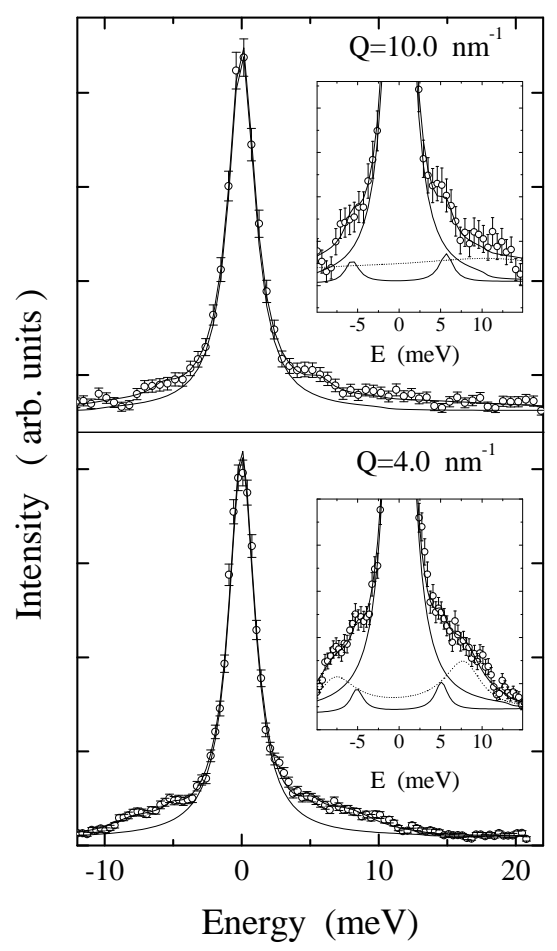

Figure 5. The IXS spectra of water at $T=5 \mathrm{C}$ (open circles) shown together with the total fits and the elastic components at the indicated $q$ values. The data are normalised to their maximum intensity corresponding $t$ ) 2.8 and 2.4 counts/sec (total counts 1100 and 500) at $q=4$ and 10 $\mathrm{nm}^{-1}$ respectively. The insets emphasise the weakly dispersing features at $\approx 4-5 \mathrm{meV}$; here the experimental data are shown together with the total fit and the three individual components (elastic peak, high and low energy inelastic contributions.

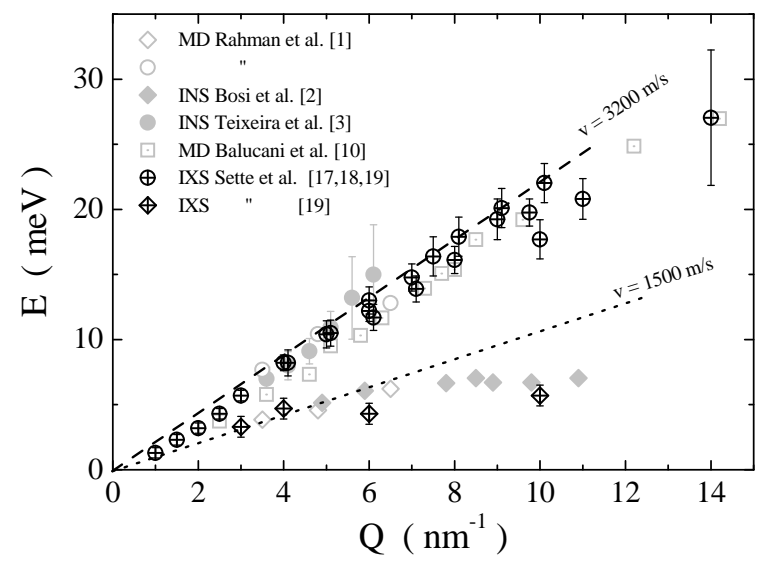

Figure 6. Excitation energies, $\Omega(q)$ of the DHO model, from the IXS experiments. The crossed circles refer to the dispersing excitation and the crossed diamonds to the weakly dispersing ones. The dashed line, with a slope of $3200 \mathrm{~m} / \mathrm{s}$, results from a fit of the IXS $\Omega(q)$ for $q \geqslant 4 \mathrm{~nm}^{-1}$. The dotted line is the dispersion relation expected for the prosecution at high $q$ of the hydrodynamics sound modes $(\approx 1500 \mathrm{~m} / \mathrm{s})$. The symbols in light grey are the data already reported in figure 2 .

a continuous modification of the apparent velocity of sound, $c(q)=\Omega(q) / q$. Indeed, the value of $3200 \mathrm{~m} / \mathrm{s}$ at $q=4 \mathrm{~nm}^{-1}$ decreases to $2000 \mathrm{~m} / \mathrm{s}$ at $q=1 \mathrm{~nm}^{-1}$ (see figure 8).

To summarize, the early IXS works and their simple lineshape analysis, beside confirming previous studies on the existence of two excitations at large $q$, shows that below a certain $q$ value 


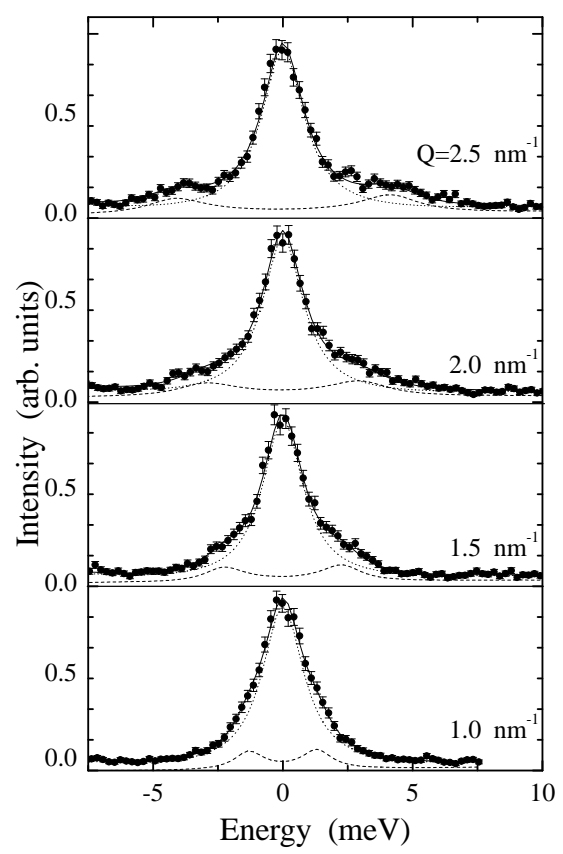

Figure 7. The IXS spectra of water at $T=5 \mathrm{C}$ (full circles) shown together with the total fits and the individual components at the indicated $q$ values. The data are normalized to their maximum intensity corresponding t 1.4, 1.2, 1.1, 1.0 counts/sec and total counts of 450, 360, 360,350 at $q=1.0,1.5,2.0,2.5 \mathrm{~nm}^{-1}$ respectively.

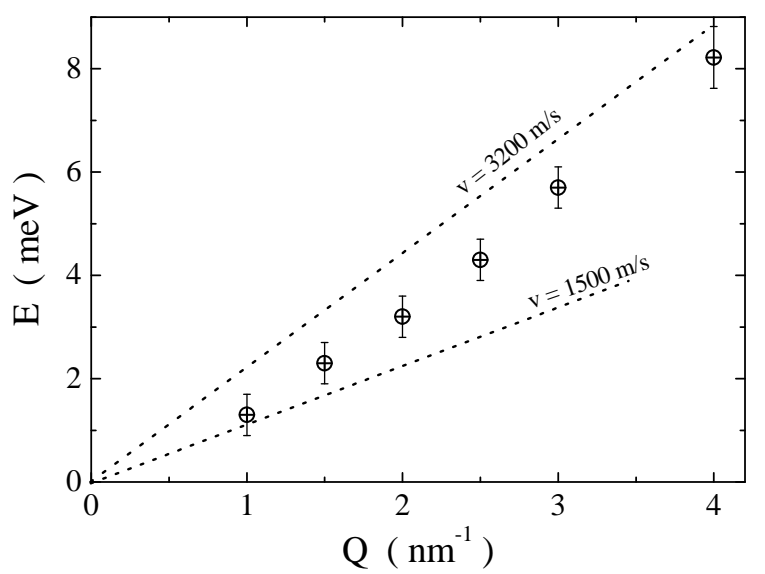

Figure 8. Excitation energies, $\Omega(q)$, (crossed circles) in the low $q$ region, where the transition from fast towards normal sound takes place, as emphasized by the two lines corresponding to the fast and normal sound branches.

only one excitation survives, and the sound velocity associated with this collective excitations progressively changes from the "fast" to the ordinary sound values with decreasing $q$-value. This experimental result implies that the "fast" sound is the continuation at high $q$ of the acoustic branch mode.

It is worth noting that only at those $q$ values where the speed of sound equals the "fast" sound value, one observes the existence of two modes. It is, therefore, possible to hypothesize that there exists a characteristic time scale $\tau$ where the density fluctuations change from the macroscopic to a solid-like elastic behavior. Correspondingly, there exists a frequency $\Omega_{\mathrm{o}}=1 / \tau$ that marks the transition between a liquid-like behavior $\left(\omega<\Omega_{0}\right)$ and a solid-like one $\left(\omega>\Omega_{0}\right)$. In the latter regime, the system has an increased sound velocity ("fast sound") and supports transverse 
excitations (dispersionless branch) [23]. Both the fast sound and the existence of a second branch, therefore, got their ultimate origin from the existence of a structural relaxation process. This "viscoelastic" hypothesis of the origin of the observed phenomenology at high frequency in liquid water has been further supported by the comparison of the dynamics in water and in hexagonal ice $[22]$ and by a molecular dynamics simulation of the longitudinal and transverse current correlation functions [24].

In conclusion [25], the analysis of the $q$ dependence of the IXS spectra of liquid water, the comparison of these spectra with those of hexagonal ice, and the analysis of the longitudinal and transverse current spectra calculated by MD simulations, show that the high frequency dynamics can be described within the same viscoelastic framework already used for other molecular liquids for a long time.

\section{An alternative explanation}

An alternative description of the complex features of the water dynamics is the description provided by the phenomenological interaction model proposed in 1999 by C. Petrillo et al. [26] and by F. Sacchetti et al. [27]. The model is based on the idea that leaving an elementary excitation, with an associated linear dispersion, to interact with a dispersionless mode brings about a splitting of the low-frequency from the high-frequency branches. In [26] it was shown that the interaction model, although in a rather crude and extremely simplified manner with respect to the richness and complexity of the water dynamics, is capable of accounting for the observed excitations and their dispersion, namely the dispersionless mode and the linearly dispersing acoustic-like mode which is associated to a low propagation velocity at low wavevector transfer and to a high velocity at large wavevector transfer.

In other words, the energy of the "normal sound" mode, slope of about $1.5 \mathrm{~km} / \mathrm{s}$, on increasing " $q$ " reaches an energy of $\approx 5 \mathrm{meV}$ (around $q=3$ inverse nanometer). At this $q$ value, the normal sound branch and the dispersionless branch "interact" together, with a result that is well know, for example, in the physics of polaritons: the branch linearly dispersing at low $q$, bends and becomes, at high $q$, almost dispersionless. The other branch, dispersionless at low $q$, acquires, at high $q$, a linear dispersion with a sound velocity larger with respect to the sound velocity of the other branch at low $q$. This situation, for the case of water, is represented in figure 9 .

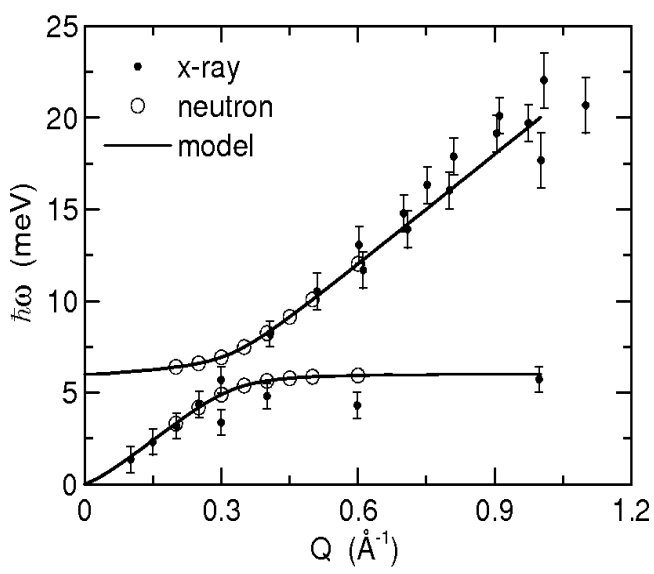

Figure 9. Dispersion relations of the collective excitation in water according to the interaction model of $[26,27]$. The continuous lines are the dispersion curves associated to the two interacting branches. The neutron data $[26,27]$ are identified by open circles. The x-ray data resulting from the experiment and the analysis are shown as dots. Figure from [27].

The "viscoelastic" and the "two-mode interaction" schemes are both phenomenological, and both of them suggest possible interaction mechanisms of the density fluctuations with some other degrees of freedom of the system, as a key to the explanation of the sound propagation in water. 
In the structural relaxation model, the relaxation time is associated with the structural relaxation, which, in turn, is most likely related to the formation and breaking of hydrogen bonds, and the collective mode propagates in a medium which may appear as a solid-like network of molecules or as an ordinary liquid structure, depending on the mode frequency. In the interaction model, the interaction between the collective (density fluctuation) mode and the system dynamics is essentially confined to the $\approx 6 \mathrm{meV}$ branch. Under the both interpretation schemes, the interactions of the collective excitation are treated on empirical basis, although the different microscopic mechanisms lead to a different interpretation of the ordinary to fast sound transition in water.

In both models, the density fluctuations interact with something else: a dispersionless, opticlike, mode (a mode with finite energy - $\approx 6 \mathrm{meV}$ - and a lifetime, or broadening, that is not relevant to the description of the observed phenomenology) in the "two-mode interaction" scheme, and a relaxation mode (a mode with zero energy and a broadening $-1 / \tau$ that defines all its properties) in the "viscoelastic" scheme. Up to this point, the experimental information available is not sufficient to assess the validity of one model against the other and both could be used as a starting point for interpreting the complex features of the water dynamics. There is, however, a crucial experiment that could solve the problem, and indeed did it.

\section{Temperature dependence of the high frequency dynamics}

In the "two-mode interaction" scheme the significant exchanged momentum (energy) value, i. e. the ideal intersection between the low $q$ linearly dispersing branch and the dispersionless branch, is temperature independent (beside the small effect associated with the temperature dependence of the density, of the adiabatic sound velocity, etc.). On the contrary, in the viscoelastic model, the significant $q_{\mathrm{o}}\left(\Omega_{\mathrm{o}}\right)$ value, being defined by $\Omega_{\mathrm{o}}=c_{\mathrm{o}} q_{\mathrm{o}}=1 / \tau$, is strongly temperature dependent, as a consequence of the strong $T$-dependence of the relaxation time $\tau$. A detailed temperature dependent study of the high frequency dynamics of liquid water has been used to discriminate between the two models in favor of the viscoelastic description.

The IXS study regarding the temperature dependence of the transition from normal to fast sound in liquid water has been performed in the $T=260-570 \mathrm{~K}$ and $q=1-12 \mathrm{~nm}^{-1}$ regions $[28,29]$. In order to emphasize the thermal effects, and to minimize the modification of the relaxation dynamics due to large variations of the excluded volume, in this experiment the density was kept as constant as possible within the experimental capabilities of adjusting the pressure in the $0-2 \mathrm{kbar}$ range. The IXS spectra were measured at different $(q, T, P)$ points. The $q$-dependence was studied in the $1-12 \mathrm{~nm}^{-1}$ region at the temperatures of 278,373 , and $493 \mathrm{~K}$. The $T$-dependence was studied at the $q$ values of 2,4 and $7 \mathrm{~nm}^{-1}$ in the $260-570 \mathrm{~K}$ region. The pressure, selected according to the Equation Of State (EOS) [30], was varied to keep the density, $\rho \approx 1.00 \mathrm{~g} / \mathrm{cm}^{3}$. The points at $T<270 \mathrm{~K}$ were taken at $P=2 \mathrm{kbar}$, corresponding to $\rho \approx 1.02-1.07 \mathrm{~g} / \mathrm{cm}^{3}$, while in those measured at $T>410 \mathrm{~K}$, also taken at $P=2 \mathrm{kbar}$, the density was in the range $\rho \approx 1.00-0.96 \mathrm{~g} / \mathrm{cm}^{3}$.

The energy dispersion of the inelastic signal with $q$ is reported in figure 10 at the selected temperatures of 278,373 and $493 \mathrm{~K}$. One observes that the deviation of the dispersion curve from the straight line, whose slope corresponds to $c_{\mathrm{O}}$ as obtained from the EOS, takes place at increasing $q$ values with increasing temperatures. In figure 10 this has been emphasized by plotting the three dispersion curves one on top of each other. In this figure, the values of $\Omega(q, T)$ have been scaled by the ratio $c_{\mathrm{o}}(278 \mathrm{~K}) / c_{\mathrm{o}}(T)$, where $c_{\mathrm{o}}$ is the adiabatic sound velocity obtained from the EOS [30], and the full line represents the adiabatic sound dispersion $\Omega(q)=c_{\mathrm{o}}(278 \mathrm{~K}) q$. The scaling of the excitation energy to the adiabatic sound velocity at $T=278 \mathrm{~K}$ permits to emphasize that the transition of the apparent sound velocity $\Omega(q) / q$ from the adiabatic $c_{\mathrm{o}}$ value to the high frequency limit, $c_{\infty}$, takes place at a $q$ value which is strongly temperature dependent. In the dispersion at $T=278 \mathrm{~K}$, the deviation from $c_{\mathrm{o}}$ can be already observed at $\approx 1 \mathrm{~nm}^{-1}$, while, at $T=373 \mathrm{~K}$ and $T=493 \mathrm{~K}$, this deviation is observed at $q$ values larger than 3 and $6 \mathrm{~nm}^{-1}$, respectively.

The behavior summarized in figure 10 provides an experimental evidence that the mechanism underlying the observed transition is of dynamical origin, and, in fact, is likely to be due to a 


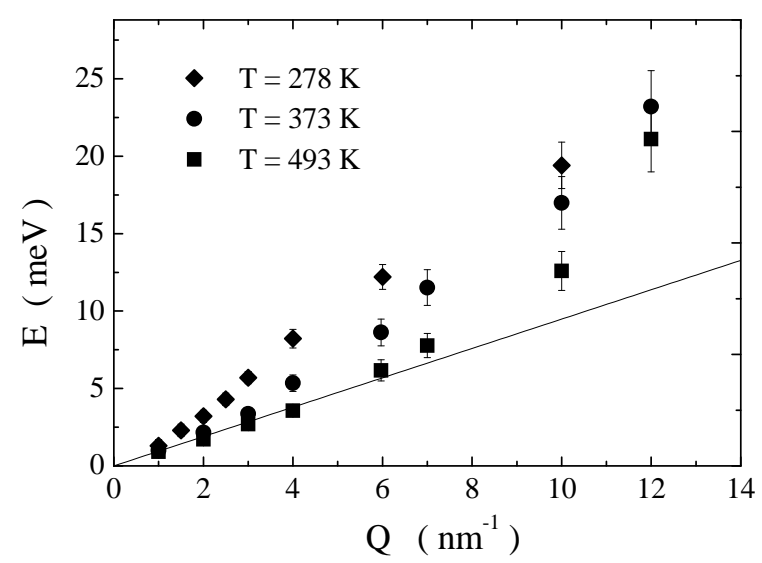

Figure 10. Dispersion relation of the $\Omega(q)$ parameter as a function of $q$ at $T=278 \mathrm{~K}$ (full diamonds), $373 \mathrm{~K}$ (full circles), and $493 \mathrm{~K}$ (full squares). The excitation values have been scaled by the factor $c_{\mathrm{o}}(278 \mathrm{~K}) / c_{\mathrm{o}}(T)$, with $c_{\mathrm{o}}(T)$ values as obtained from the EOS [30]. This has been done to emphasize in the same plot the departure of the dispersion relation from the $c_{\mathrm{o}}(T) q$ law, shown by a solid line, which is valid in the $q \rightarrow 0$ limit. This departure takes place at increasing $q$ values with increasing temperatures.

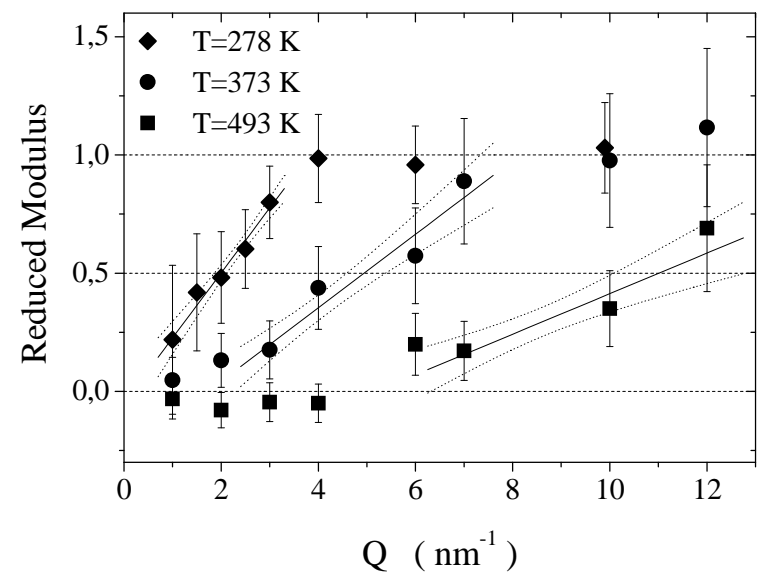

Figure 11. $q$-dependence of the reduced apparent modulus, $M_{\mathrm{r}}$, at the indicated temperatures (symbols as in figure 17). The $q$ values at which the transition takes place, $q_{\mathrm{o}}$, have been determined by the condition $M_{\mathrm{r}}=0.5$. This has been found by the linear fits to the data, shown (full lines) together with their $\pm 1 \sigma$ prediction bands (dotted lines).

relaxation process. The temperature dependence of its characteristic relaxation time, $\tau$, is then the cause of the strong temperature dependence of the $q$ value, $q_{\mathrm{o}}$, at which the transition is observed.

A quantitative determination of both $q_{\mathrm{o}}$ and $\tau$ can be obtained by introducing the apparent longitudinal elastic modulus: $M=\rho_{\mathrm{w}} c^{2}(q, T)$ (here $\rho_{\mathrm{w}}$ is the mass density). In the simple Debye approximation for the relaxation process, the frequency dependence of $M$, leading to the dispersion from its low frequency value $M_{\mathrm{o}}=\rho_{\mathrm{w}} c_{\mathrm{o}}^{2}$ to its high frequency one $M_{\infty}=\rho_{\mathrm{w}} c_{\infty}^{2}$, is given by:

$$
M=M_{\infty}+\frac{M_{\mathrm{o}}-M_{\infty}}{1+\mathrm{i} \omega \tau} .
$$

Introducing the reduced apparent modulus $M_{\mathrm{r}}$ as:

$$
M_{\mathrm{r}}=\frac{M-M_{\mathrm{o}}}{M_{\infty}-M_{\mathrm{o}}}
$$

the values of $\tau$ can be determined by the condition $\operatorname{Re}\left(M_{\mathrm{r}}\right)=0.5$. The calculation of $M_{\mathrm{r}}(q, T)$ 
from the measured apparent sound velocity requires the knowledge of $c_{\mathrm{o}}$ and $c_{\infty}$. For $c_{\mathrm{o}}(T)$, we used the values from the EOS [30] and we assumed them to be $q$ independent. We also assumed a $T$ and $q$ independent value of $c_{\infty}=3200 \mathrm{~m} / \mathrm{s}$ (derived from the IXS measurements at $T=278 \mathrm{~K}$ [19]). Within these approximations, we obtained from the data reported in figure 10 , the $M_{\mathrm{r}}$ values shown in figure 11 . This allows us to determine the momentum transfer value $q_{\mathrm{o}}$ from the condition $M_{\mathrm{r}}=0.5$ at the considered temperature. The values for $\tau(T)$ are then derived as $\tau(T)=\Omega_{\mathrm{o}}^{-1}=\Omega\left(q_{\mathrm{o}}, T\right)^{-1}$, where $\Omega\left(q_{\mathrm{o}}, T\right)$ is obtained interpolating the $\Omega(q, T)$ reported in figure 10. Similarly, from the sets of measurements performed at $q=2,4$ and $7 \mathrm{~nm}^{-1}$ as a function of temperature, we obtained the $\Omega(q, T)$ values which lead to the $M_{\mathrm{r}}(q, T)$ values reported in figure 11. Here, from the condition $M_{\mathrm{r}}(q, T)=0.5$, one obtained the temperature $T_{t}$, where the selected momentum transfer becomes $q_{\mathrm{o}}$. Therefore, $\tau(T)=\Omega\left(q, T_{\mathrm{o}}\right)^{-1}$, where $\Omega\left(q, T_{\mathrm{o}}\right)$ is obtained interpolating the $\Omega(q, T)$.

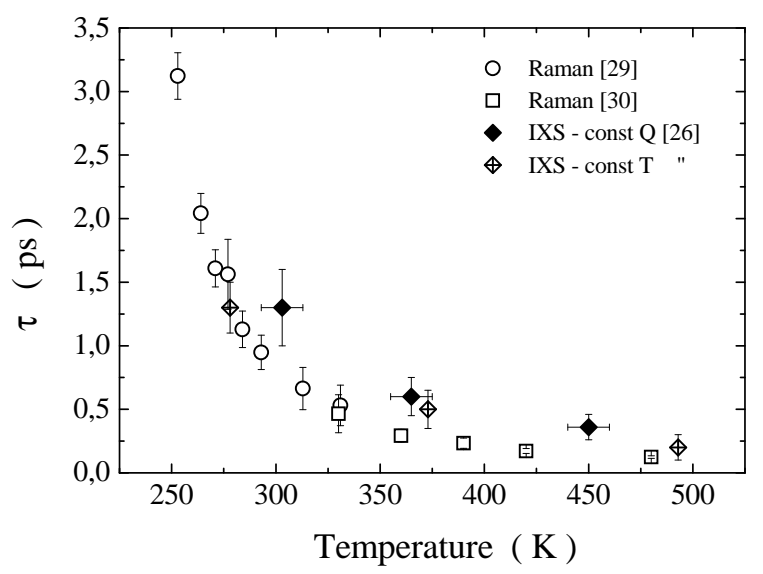

Figure 12. The relaxation time $\tau$ as obtained from the analysis of the apparent reduced moduli reported in figures 10 (crossed diamonds) and 11 (full diamonds) are shown together with those derived from depolarised Raman scattering in [31] (open circle) and [32] (open square).

The values of $\tau(T, q)$ derived from figures 10 and 11 are reported in figure 12 . This quantity changes from $1.3 \mathrm{ps}$ at $280 \mathrm{~K}$ to $0.2 \mathrm{ps}$ at $490 \mathrm{~K}$. In spite of the fact that the present measurements were performed at a constant density, the derived $\tau$ values are consistent with other determinations performed along the coexistence curve by the linewidths of the depolarised Raman scattering [31,32] by ultrasound absorption and viscosity measurements [33], by Brillouin light scattering data [14,15], and by molecular dynamics simulations [11].

Summarizing the work described in this paragraph, the study of the temperature dependence of the $S(q, \omega)$ in liquid water has shown that the transition between the low frequency adiabatic sound velocity towards its high frequency limit takes place at a $q_{\mathrm{o}}$ value which is strongly temperature dependent. This demonstrates that such a transition is due to a relaxation process and rules out the interaction model. In the latter model, indeed, the transition point is expected to be almost $T$-independent, as a consequence of the slight temperature dependence of both the low frequency sound velocity and the energy of the dispersionless branch. Moreover, the phenomenology found in the temperature and $q$ dependencies of the excitation energies of the longitudinal sound mode strongly resembles the one observed in glass forming liquids undergoing the $\alpha$ relaxation process. For these systems, a quantitative viscoelastic analysis is routinely performed.

\section{Viscoelastic analysis of liquid water}

The $S(q, \omega)$ spectra of water can be represented by a refined and informative hydrodynamic model which accounts for both the elastic and the inelastic spectral components. This formalism allows one to extract the values for infinite frequency sound velocity, for the structural relaxation time and for other parameters that can be compared with those derived by means of lower frequency 
techniques. In this way, a consistent experimental picture of the relaxation process taking place in water can be derived.

In the viscoelastic approach to the liquid dynamics, one is essentially concerned with the normalized correlation function, $\Phi_{q}(t)$, of the density fluctuations:

$$
\Phi_{q}(t)=\frac{\left\langle\delta \rho_{q}^{*}(0) \delta \rho_{q}(t)\right\rangle}{\left\langle\delta \rho_{q}^{*}(0) \delta \rho_{q}(0)\right\rangle}
$$

where $\delta \rho_{q}(t)$ is the $q$-component of the fluctuation of the microscopic number density, $\rho(r, t)$. The dynamic structure factor, $S(q, \omega)$, is then defined as:

$$
S(q, \omega)=S(q) \int_{-\infty}^{\infty} \mathrm{d} t \mathrm{e}^{-\mathrm{i} \omega t} \Phi_{q}(t),
$$

where we have introduced the static structure factor:

$$
S(q)=\left\langle\delta \rho_{q}^{*}(0) \delta \rho_{q}(0)\right\rangle=\frac{1}{2 \pi} \int_{-\infty}^{\infty} \mathrm{d} \omega S(q, \omega) .
$$

An equation of motion for $\Phi_{q}(t)$ can be written in the form of a generalized Langevin equation $[21,34]$ :

$$
\frac{\partial^{2} \Phi_{q}(t)}{\partial t^{2}}+\omega_{\mathrm{o}}^{2}(q) \Phi_{q}(t)+\int_{0}^{t} \mathrm{~d} t^{\prime} m_{q}\left(t-t^{\prime}\right) \frac{\partial \Phi_{q}\left(t^{\prime}\right)}{\partial t^{\prime}}=0
$$

analogously, in the frequency space, the dynamic structure factor can be written as:

$$
S(q, \omega)=\frac{2 v_{\mathrm{o}}^{2} q^{2}}{\omega} \operatorname{Im}\left[\omega^{2}-\omega_{\mathrm{o}}(q)^{2}-\mathrm{i} \omega m_{q}(\omega)\right]^{-1} .
$$

The parameter $\omega_{\mathrm{o}}(q)$ introduced in equations 6 and 7 is completely determined once one requires that the second sum rule for $S(q, \omega)$ be fulfilled, and it turns out to be:

$$
\omega_{\mathrm{o}}^{2}(q)=\frac{\left(q v_{\mathrm{o}}\right)^{2}}{S(q)}
$$

where $v_{\mathrm{o}}$ is the classical thermal speed which is defined in terms of the molecular mass, $M$, and the Boltzmann constant, $K_{\mathrm{B}}$, being $v_{\mathrm{o}}^{2}=K_{\mathrm{B}} T / M$. Moreover, in equation $6(7)$ we have introduced the second memory function, $m_{q}(t)$ (and its Fourier transform $m_{q}(\omega)$ ), of the so-called Zwanzig-Mori expansion of $\Phi_{q}(t)$ [35]. Alternatively, equations 6 and 7 can be simply considered as equations which define $m_{q}(t)$. As a matter of fact, the real advantage of equations 6 and 7 is that the introduction of simple models for $m_{q}(t)$ - rather than directly for $\Phi_{q}(t)$ - guarantees that at least the first two non-zero spectral moments of $S(q, \omega)$ are always respected. Clearly, at this stage, equation $6(7)$, being a formal expression, correctly describes the atomic dynamics at any time (frequency, energy) and wavenumber.

According to the different kind of dynamics which is probed, the $(q, \omega)$ space is usually divided into different regions.

i) The condition $\omega \tau \ll 1$ defines the region of the $(q, \omega)$ space where simple Hydrodynamics holds. Here, the changes in the liquid structure induced by the density fluctuation are supposed to take place sufficiently slowly for the system to be considered in a state of local thermodynamic equilibrium. Under this condition it is possible to obtain a closed set of equations describing the space-time variations of the conserved variables, namely the particle number and the current and energy densities. This description becomes explicit when the values of appropriate thermodynamic derivatives and transport coefficients are specified. The results of such calculations are available in analytical form and can be expressed by equation 6 with the following memory function [34]:

$$
m_{q \rightarrow 0}(t)=\omega_{\mathrm{O}}^{2}(q)[\gamma-1] \mathrm{e}^{-D_{\mathrm{T}} q^{2} t}+2 \nu_{1} q^{2} \delta(t)
$$


where $\gamma=C_{\mathrm{P}} / C_{\mathrm{V}}$ is the constant pressure to constant volume specific heat ratio; $D_{\mathrm{T}}=\kappa /\left(\rho C_{\mathrm{V}}\right)$, where $\kappa$ is the the thermal conductivity; and $\nu_{1}$ is the kinematic longitudinal viscosity.

ii) If condition $\omega \tau \ll 1$ fails, one enters the region of the so-called Molecular Hydrodynamics [34]. In this region the atomic dynamics is influenced by relaxational effects. In this regime, if an external disturbance is applied to a liquid system, the system has no time to respond before the perturbation is removed and the pre-existing equilibrium state is unchanged; in this situation the system behaves like a solid, and actually the condition $\omega \tau \gg 1$ can be used to define the purely elastic state. Measurements made in between these two time scales, i.e. in the "relaxation region", enable one to determine the relaxation time.

The smooth transition from the simple hydrodynamic regime to the molecular one is the main argument used in order to extend the hydrodynamic description by retaining the formal structure of the equations, but replacing the thermodynamic derivatives and the transport coefficients with functions which can vary both in space (or wavenumber) and time (or frequency). Thus, equation 9 can be generalized in the following way [34]:

$$
m_{q}(t)=\omega_{\mathrm{o}}^{2}(q)[\gamma(q)-1] \mathrm{e}^{-D_{\mathrm{T}}(q) q^{2} t}+K_{\mathrm{l}}(q, t),
$$

where $\gamma(q)$ and $D_{\mathrm{T}}(q)$ are the $q$ dependent generalizations of the corresponding thermodynamic quantities, and $K_{1}(q, t)$ is directly related to the longitudinal kinematic viscosity. In fact, the requirement that equation 10 joins equation 9 in the simple hydrodynamic regime imposes the following condition:

$$
\lim _{q \rightarrow 0} \int_{0}^{\infty} \mathrm{d} t K_{\mathrm{l}}(q, t)=q^{2} \nu_{\mathrm{l}} .
$$

In the molecular hydrodynamic approach that we just recalled here, a specific model for $m_{q}(t)$ has to be introduced. In the frame of equation 10, the simplest choice for $K_{1}(q, t)$ is an exponential decay. This choice, which is usually known as the viscoelastic model, allows for a reasonably good description of the evolution of $S(q, \omega)$ with $q$ for $q \approx q_{m}$, where $q_{m}$ denotes the first diffraction peak position. However, for $q \approx q_{m} / 10$, as in our case (water has a structured first diffraction peak which approximatively covers the $20-30 \mathrm{~nm}^{-1}$ range), the viscoelastic model begins to fail. This is usually explained by saying that, when decreasing $q$ below $q_{m}$, the memory function splits into two contributions. i) The first one is related to molecular vibrations in the local environment, which induce a loss of correlation at the very early stages, usually on the $10^{-13} \mathrm{~s}$ time-scale, with almost no temperature dependence: the so-called microscopic decay [36,37]. ii) The second contribution, instead, is thought to be basically due to the couplings of different $q$-components of density fluctuations, and - on the whole - corresponds to the structural relaxation previously referred to [36]. This latter contribution is characterized by a decay time which strongly depends on temperature, changing from $\approx 10^{-12} \mathrm{~s}$ in the normal liquid phase up to about $100 \mathrm{~s}$ close to the glass transition temperature. As a consequence of this conceptual picture, and beginning with the classical MD study by Levesque et al. on the Lennard-Jones liquid near its triple point [38], it is customary to represent the function $K_{l}(q, t)$ as the sum of two exponentials. As a general result of this approach, the characteristic time of the microscopic decay turns out to be at least almost one decade in time faster than the characteristic time of the structural relaxation [38]. Thus, in order to use a model with a minimum number of parameters, here we will represent a microscopic decay with a simple Markovian term. As a matter of fact, in the next Section this simple approximation will be shown quite in detail to represent our experimental data. To summarize, our model for $K_{l}(q, t)$ reads:

$$
K_{\mathrm{l}}(q, t)=2 \gamma_{\mathrm{o}}(q) \delta(t)+\frac{q^{2}}{\rho} \Delta^{2}(q) \mathrm{e}^{-t / \tau_{\mathrm{M}}(q)},
$$

where $\gamma_{\mathrm{o}}(q)$ represents the very fast decaying contribution to $K_{\mathrm{l}}(q, t) ; \tau_{\mathrm{M}}(q)$ is the $q$-dependent time which characterizes the long time tail of $K_{1}(q, t)$; and $\Delta^{2}(q)$ is the structural relaxation strength which is related to two further important quantities, $c_{\infty}(q)$ and $c_{\mathrm{o}}(q)$ i. e. the $q$-dependent generalizations of the usual infinite frequency and adiabatic sound speeds, as:

$$
\Delta^{2}(q)=\rho\left[c_{\infty}^{2}(q)-c_{\mathrm{o}}^{2}(q)\right]
$$


In fact, the second term on the right hand side of equation 12 is in principle capable of describing the classical phenomenology of the dispersion and absorption of the sound waves, e.g. the transition of the sound speed from its low-frequency, adiabatic value, $c_{\mathrm{o}}(q)$, to the high frequency, limiting value, $c_{\infty}(q)$. Though, in principle, a more rigorous and detailed expression than a simple exponential decay could be used to represent the structural relaxation contribution [36], nevertheless one can fully account for the experimental data with a single exponential approximation, and thus there is no real need to use a more complex expression.

The first term on the right hand side of equation 9, corresponding to the thermal contribution, in contrast to the viscosity term (second term on the right hand side), is characterized by a finite decay time; it is consequently more sensible to modify the $\delta(t)$ decay of the viscous term than to speculate about possible deviations of the thermal contribution from a purely exponential decay [21]. Thus, we have approximated the thermal contribution with its counterpart at low q's, i.e. we will assume: $i) \omega_{\mathrm{o}}(q)=\omega_{\mathrm{O}}=q c_{\mathrm{T}}$, where $c_{\mathrm{T}}$ is the isothermal sound velocity; $\left.i i\right) \gamma(q)=\gamma$; and $\left.i i i\right)$ $D_{\mathrm{T}}(q)=D_{\mathrm{T}}$. Assumption $\left.i\right)$ is quite safe since $\omega_{\mathrm{o}}^{2}(q) \propto[S(q)]^{-1}[34]$ and $S(q)$ is almost flat in the $q$-range considered here $\left(0<q<7 \mathrm{~nm}^{-1}\right)$. Assumption ii) is also well verified in water in the considered $q$-range [39]. Assumption iii), however, is in principle quite poor since $D_{\mathrm{T}}(q)$ decreases of almost a factor of three when $q$ increases from its zero limit up to $7 \mathrm{~nm}^{-1}$ [39]. However, this is not really a relevant problem. In fact, at $q=0$, being $\left(q^{2} \Delta^{2}\right) /\left(\rho \omega_{\mathrm{o}}^{2}\right) \approx 3[39]$ and being $\gamma \leqslant 1.2$, the strength of the thermal contribution, $\omega_{\mathrm{o}}^{2}(\gamma-1)$, is about one order of magnitude lower than that corresponding to the structural relaxation, $q^{2} \Delta^{2} / \rho$, and such a situation is not expected to change much when increasing $q$ in the $q$ range probed here. Thus, assumption iii) simply amounts to the neglect of the $q$-dependence of the characteristic time of an exponential contribution whose strength is $\approx 10 \%$ of that of the structural relaxation.

To summarize, in order to describe the IXS experimental spectra, we have used equation 7 together with the Fourier transform of the following model for the memory function:

$$
m_{q}(t)=\omega_{\mathrm{o}}^{2}(\gamma-1) \mathrm{e}^{-D_{\mathrm{T}} q^{2} t}+2 \gamma_{\mathrm{o}}(q) \delta(t)+\frac{q^{2}}{\rho} \Delta^{2}(q) \mathrm{e}^{-\left(\omega_{\mathrm{o}}^{2}(q) t\right) /\left(\omega_{\infty}^{2}(q) \tau_{\mathrm{c}}(q)\right)} .
$$

In this equation, there has been introduced the compliance relaxation time $\tau_{\mathrm{c}}(q)$ defined as $\tau_{\mathrm{c}}(q)=$ $\tau_{\mathrm{M}}(q)\left[\omega_{\infty}^{2}(q) / \omega_{\mathrm{o}}^{2}(q)\right]$

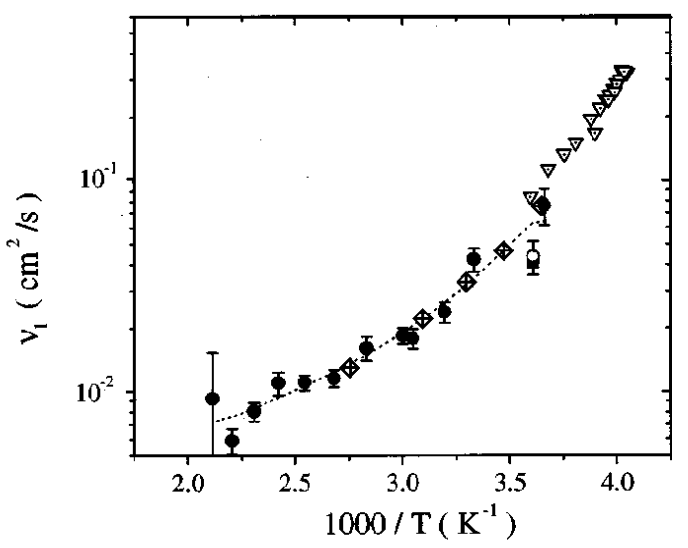

Figure 13. $T$-dependence of the kinematic longitudinal viscosity, $\nu_{1}$, obtained from the best fit parameters (full circles for the $\rho \approx 1 \mathrm{~g} / \mathrm{cm}^{3}$ data and open circle for the $\rho \approx 1.1 \mathrm{~g} / \mathrm{cm}^{3}$ one). The data are shown on an Arrhenius plot. IXS data are compared with US measurements at $25-50 \mathrm{MHz}$ (crossed diamonds) [40], and BLS ones at $\approx 10 \mathrm{GHz}$ (open squares) [15]. Both the reported US and BLS data correspond to $\rho \approx 1 \mathrm{~g} / \mathrm{cm}^{3}$. Moreover, shear viscosity data, multiplied by a factor of 4 (which is the almost $T$ - and $P$-independent ratio between the longitudinal and the shear viscosity [40]), are also shown (dotted lines) in order to give an indication of the expected $T$-dependence of $\nu_{1}$. The good agreement among all the reported data can be appreciated. Figure from [42]. 
The fitting of the IXS spectra with the $S(q, \omega)$ modelled by the viscoelastic equations summarized before, beside giving a very good representation of the data, also provides different parameters (e. g. the kinematic viscosity and sound velocities) that can be compared with independent determinations. The comparison of these data, as shown in figures 13 and 14, reveals that the temperature dependence of both the longitudinal viscosity and the adiabatic sound velocity determined by fits to the IXS data are consistent with independent measurements (US and BLS), thus giving strong support to the viscoelastic interpretation of the water dynamics [42].

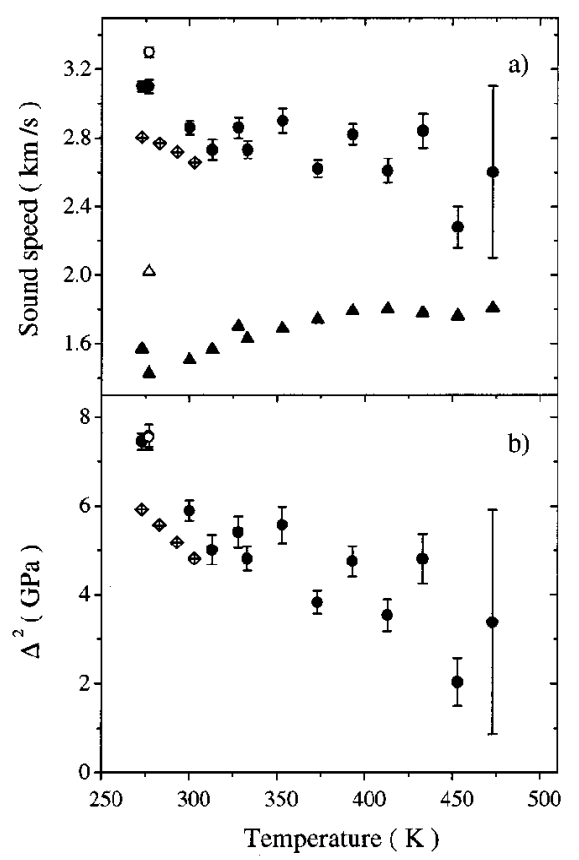

Figure 14. $T$-dependence of the infinite frequency sound velocity (a) and of the related structural strength (b) for IXS data (full circles for the $\rho \approx 1 \mathrm{~g} / \mathrm{cm}^{3}$ data and open circle for the $\rho \approx 1.1$ $\mathrm{g} / \mathrm{cm}^{3}$ one). For comparison, US results (crossed diamonds), corresponding to a density of $\approx 1$ $\mathrm{g} / \mathrm{cm}^{3}$ [41], are also reported for both quantities. Moreover, for the sake of comparison, we also report in a) the adiabatic speed values (full triangles for the $\rho \approx 1 \mathrm{~g} / \mathrm{cm}^{3}$ data and open triangle for the $\rho \approx 1.1 \mathrm{~g} / \mathrm{cm}^{3}$ one). Figure from [42].

To summarize, the whole set of results obtained for the structural relaxation demonstrates the suitability of the viscoelastic model to the description of the $S(q, \omega)$ of water up to the $\mathrm{THz}$ frequency range. The IXS technique shows its full potential as a very high frequency hypersonic technique: when used together with the traditional mechanical, US and BLS techniques, it permits to study the structural relaxation parameters entering the $S(q, \omega)$ spectrum in the whole frequency region going from $10^{-2}$ to $10^{12} \mathrm{~Hz}$.

In a nutshell, ten years of IXS investigation allows one to reach the conclusion that the fast sound phenomenon observed in water is associate to a viscoelastic transition between a low-frequency (low q) regime, where the viscous behavior is emphasized, and high-frequency regime, where there is observed the elastic behavior of the system that is dominant.

The viscoelastic description of the dynamics in liquid water has been further confirmed by other techniques (for example the Inelastic UV Scattering technique [43,44]) and in an extended state points region, including high pressure [45] and supercritical conditions [46].

\section{Final remarks}

In this review, following the historical course of events, we have reported the development of the discussions that took place around the so-called fast sound phenomenon in liquid water, starting 
from its discovery [1], up to the more recent IXS and INS investigations. We hope to have made clear the relevance, for such kind of studies, of the IXS technique, that allows one to extend the frequency-momentum region beyond the limits imposed by the kinematic to the INS technique. Actually, the problem of fast sound in water has been the very first research field where the IXS technique has been applied, but other fields benefitted by this technique.

There is another facet of the fast sound issue that is worth emphasizing. Many time in the past, the liquid water-maybe because of its indisputable central role in the "Life, the Universe and Everything" [47] - has been subject of attention by the "pathological Science". Among many others, one can recall the cases of the "Polywater" [48] and of the "Memory of Water" [49]. The fast sound issue is certainly not at the same level of these two examples, nevertheless it has attracted the attention of those who want to find the "exceptionality" of water everywhere. Once more, as in the previous cases, the water has been demonstrated to be nothing else but a liquid similar to many others, also sharing with the other the property to be viscoelastic.

\section{References}

1. Rahman A.,Stillinger F.H., Phys. Rev. A, 1974, 1, 368.

2. Bosi P. et al., Il Nuovo Cimento Lett., 1978, 21, 436.

3. Teixeira J., Bellissent-Funel M.C., Chen S.H., Dorner B., Phys. Rev. Lett., 1985, 54, 2681.

4. Impey R.W., Madden P.A., McDonald I.R., Mol. Phys., 1982, 46, 513.

5. Wojcik M., Clementi E., J. Chem. Phys., 1986, 85, 6085.

6. Ricci M.A., Rocca M.D., Ruocco G., Vallauri R., Phys. Rev. Lett., 1988, 61, 1958.

7. Ricci M.A., Rocca M.D., Ruocco G., Vallauri R., Phys. Rev. A, 1989, 40, 7226.

8. Sastry S., Sciortino F., Stanley E., J.Chem.Phys., 1991, 95, 7775.

9. Balucani U., Ruocco G., Sampoli M., Torcini A., Vallauri R., Chem. Phys. Lett., 1993, 209, 408.

10. Balucani U., Ruocco G., Torcini A., Vallauri R., Phys. Rev. E, 1993, 47, 1677.

11. Sciortino F., Sastry S., J. Chem. Phys., 1994, 100, 3881.

12. Tozzini V., Tosi M.P., Phys. Chem. Liq., 1996, 33, 191.

13. Balucani U., Brodholt J.P., Vallauri R., J. Phys. C, 1997, 8, 9269.

14. Magazú S., Maisano G., Majolino D., Mallamace F., Migliardo P., Aliotta F., Vasi C., J. Chem. Phys., 1989, 93, 942, Maisano G., Migliardo P., Aliotta F., Vasi C., Wanderlingh F., D’Arrigo G., 1984, Phys. Rev. Lett. 52, 1025.

15. Cunsolo A., Nardone M., J. Chem. Phys., 1996, 105, 3911.

16. Bermejo F.J., Alvarez M., Bennington S.M., Vallauri R., Phys. Rev. E, 1995, 51, 2260.

17. Sette F., Ruocco G., Krisch M., Bergmann U., Masciovecchio C., Mazzacurati V., Signorelli G., Verbeni R., Phys. Rev. Lett., 1995, 75, 850.

18. Ruocco G., Sette F., Krisch M., Bergmann U., Masciovecchio C., Mazzacurati V., Signorelli G., Verbeni R., Nature, 1996, 379, 521.

19. Sette F., Ruocco G., Krisch M., Masciovecchio C., Verbeni R. Bergmann U., Phys. Rev. Lett., 1996, $\mathbf{7 7}, 83$.

20. Fak B., Dorner B., Institute Laue Langevin. Grenoble, France, technical report No. 92FA008S, 1992.

21. Balucani U., Zoppi M. Dynamics of the Liquid State, Oxford Science Publ., Oxford, 1994.

22. Ruocco G., Sette F., Krisch M., Bergmann U., Masciovecchio C., Verbeni R., Phys. Rev. B, 1996, 54, 14892 .

23. Pontecorvo E., Krisch M., Cunsolo A., Monaco G., Mermet A., Verbeni R., Sette F., Ruocco G. Physical Review E, 2005, 71, 011501.

24. Sampoli M., Ruocco G., Sette F., Phys. Lett., 1997, 79, 1678.

25. Ruocco G., Sette F. Journal of Physics: Condensed Matter, 1999, 11, R259.

26. Petrillo C., Sacchetti F., Dorner B., Suck J.-B., Phys. Rev. E, 2000, 62, 3611.

27. Sacchetti F., Suck J.-B., Petrillo C., Dorner B., Phys. Rev. E, 2004, 69, 061203.

28. Cunsolo A., Ruocco G., Sette F., Masciovecchi C., Mermet A., Monaco G., Sampoli M., Verbeni R., Phys. Rev. Lett., 1999, 82, 775.

29. Cunsolo A., Ruocco G., Sette F., Masciovecchi C., Mermet A., Monaco G., Sampoli M., Verbeni R., Phys. Rev. Lett., 1999, 82, 2810.

30. Kestin J., Senger J.V., J. Phys. Chem. Ref. Data, 1986, 15, 305.

31. Mazzacurati V., Nucara A., Ricci M.A., Ruocco G., Signorelli G., J. Chem. Phys., 1990, 93, 7767.

32. Fontana A., Nardone M., Ricci M.A., J. Chem. Phys., 1995, 102, 6975. 
33. Hie W.M., Doylor A.R., Litovitz T.A., J. Chem. Phys., 1966, 44, 3712; Davis C.M., Jarzynki J. in "Water: a comprehensive treatise", Frank F. Ed., 1, 443-461, Plenum, New York, 1972.

34. Boon J.P., Yip S. Molecular Hydrodynamics. Dover Publications Inc., New York, 1991.

35. Zwanzig R. In Lectures in Theoretical Physics. Brittin W. Ed., Wiley-Interscience, New-York, 1961,3, 106-141; Mori H., Progr. Theo. Phys., 1965, 33, 423.

36. Götze W. In Liquids, Freezing and the Glass Transition, Hansen J.P., Levesque D., Zinn-Justin J. Eds., North-Holland, Amsterdam, 1991, 289-503.

37. Scopigno T., Ruocco G., Sette F., Review of Modern Physics, 2005, 77, 881.

38. Levesque D., Verlet L., Kürkijarvi J., Phys. Rev. A, 1973, 7, 1690.

39. Bertolini D., Tani A., Phys. Rev. E, 1995, 51, 1091; ibidem, 1995, 52, 1699; ibidem, 1997, 56, 4135.

40. Davis C.M., Jarzynski J. In Water: a Comprehensive Treatise, Franks F. Ed., Plenum, New York, 1972, 1, 443-461.

41. Slie W.M., Donfor A.R., Jr., Litovitz T.A., J. Chem. Phys., 1966, 44, 3712.

42. Monaco G., Cunsolo A., Ruocco G., Sette F.. Physical Review E, 1999, 60, 5505.

43. Masciovecchio C., Santucci S.C., Gessini A., Fonzo S.Di, Ruocco G., Sette F., Physical Review Letters, 2004, 92, 255507.

44. Santucci S.C., Fioretto D., Comez L., Gessini A., Masciovecchio C., Physical Review Letters, 2006, 97, 225701.

45. Krisch M., Loubeyre P., Ruocco G., Sette F., Verbeni R., Cunsolo A., D'Astuto M., Le Toullec R., Lorenzen M., Mermet A., Monaco G., Verbeni R. Physical Review Letters, 2002, 89, 125502.

46. Bencivenga F., Cunsolo A., Krisch M., Monaco G., Ruocco G., Sette F. Physical Review E, 2007, 75, 051202.

47. "Life, the Universe and Everything" is a popular novel by Douglas Adams, Pan Book Ltd., London, 1982.

48. Franks Felix. Polywater, MIT Press, Cambridge, Mass. (USA), 1983.

49. For a recent review on the history of the memory of water see " $\mathrm{H}_{2} \mathrm{O}$ A biography of water", Philip Ball, Weidenfeld \& Nicolson, 1999, and Stillinger F.H., Nature, 1999, 401, 851. 


\title{
Історія “швидкого звуку” у воді
}

\author{
Дж.Руокко ${ }^{1}$, Ф.Сетте ${ }^{2}$ \\ ${ }^{1}$ Національна Рада Досліджень, Центр SOFT та фізичний факультет, Римський університет "La \\ Sapienza”, Рим, Італія \\ 2 Європейський центр синхротронної радіації, Ґренобль, Франція
}

\section{Отримано 12 лютого 2008 р.}

Стаття має на меті обговорити сучасне розуміння високочастотної динаміки у воді з наголосом на специфічне явище - так званий швидкий звук - від його першої появи в літературі аж до недавніх пояснень. Особливу роль у цій історії відіграла методика непружнього розсіяння рентгенівських променів (НРРП), яка - від її впровадження у середині 90-х років - започаткувала великий клас задач, пов'язаних з високочастотною динамікою неспорядкованих систем, таких як стекла та рідини. Результати по швидкому звуку в воді, отримані методикою НРРП, тут порівнюються з роботами по непружньому розсіянню нейтронів та моделюванню методом молекулярної динаміки. Роботи 3 НРРП дозволили експериментально продемонструвати існування у воді двох віток колективних мод: одна з лінійною дисперсією (зі спостереженою швидкістю звуку $\approx 3200$ м/с, “швидкий звук") та іншу з майже постійною енергією $(5 \div 7 \mathrm{mеB})$. Показано, що вітка з дисперсією походить від в'язкопружнього згину звичайної акустичної вітки. Дослідження цієї дисперсії швидкості звуку, що визначає перехід від звичайного звуку , $c_{o}$ до “швидкого звуку", $c_{\infty}$, як функція температури, дозволила пов'язати природу цього явища з процесом структурної релаксації, що представляє багато аналогій зі спостережуваними у склоутворюючих системах. Можливість визначити з даних НРPП значення релаксаційного часу, $\tau$, як функції температури приводить до пов'язання релаксаційного процесу зі структурною перебудовою, індукованою створенням та розривом водневих зв'язків. В рамках такого підходу є можливим визначити гідродинамічний "нормальний" режим, коли розглядаються флуктуації густини з довгим періодом осциляцій по відношенню до $\tau$, та твердотільний режим у протилежній границі. В останньому режимі флуктуації густини відчувають рідину як заморожену, а швидкість звуку є набагато більшою: це є “швидкий звук" з величиною еквівалентною швидкості звуку знайденою в кристалічному льоді.

Ключові слова: вода, непружнє розсіяння рентгенівських променів, поширення звуку, рідини, скловидні системи

PACS: $61.10 . E q, 63.50 .+x, 78.70 . C k$ 